\title{
Una interpretación del conflicto por el desabastecimiento de agua potable ocurrido durante el 2014 en el cantón de Barva de Heredia, Costa Rica
}

\author{
Diego Montero \\ Universidad de Costa Rica, San José, Costa Rica \\ montero.diego1988@gmail.com
}

\begin{abstract}
Resumen: Este artículo busca estudiar el caso de la conflictividad por el desabastecimiento en el servicio de agua que se generó en el cantón de Barva de Heredia durante el 2014. El primer objetivo consiste en describir algunos de los acontecimientos más notables de dicho conflicto, con el fin de mostrar las características principales adquiridas por la contienda, para, posteriormente, como segundo objetivo, establecer un análisis de los hechos, focalizando la atención en la organización comunal que se creó en medio de la problemática. Para lo anterior, se empleó la observación participante, noticias de prensa escrita y reportajes televisivos, así como información, imágenes y videos publicados en la página de Facebook del movimiento y en el portal YouTube.

Así, el planteamiento que se intenta defender es que para poder entender por qué surgió el conflicto entre los actores comunales y las autoridades municipales, es necesario sobrepasar su causa más inmediata, que fueron los recortes en el suministro de agua, prestándoles atención a otras variables políticas, históricas y socioculturales.

Palabras claves: Conflicto por el agua; acciones colectivas; movimiento social; organización comunal; municipalidad.
\end{abstract}

Cuadernos de Antropología

Enero-Junio 2016, 26(1), 63-84

DOI: $10.15517 /$ cat.v26i1.25262

Recibido: 26-02-2016 / Aceptado: 19-05-2016 / Publicado: 28/05/2016

Revista del Laboratorio de Etnología María Eugenia Bozzoli Vargas

Escuela de Antropología, Universidad de Costa Rica

http://revistas.ucr.ac.cr/index.php/antropologia

ISSN 2215-356X

c) (1) Cuadernos de Antropología está bajo una licencia Creative Commons Attribution-NonCommercial-ShareAlike 3.0 


\begin{abstract}
An interpretation of the conflict by the shortage in water service during 2014 in Barva de Heredia, Costa Rica
\end{abstract}

Abstract: This article seeks to study the case of the conflict by the shortage in water service that was generated in Barva de Heredia during 2014. The first objective is to describe some of the most notable events of this conflict, in order to show the main features that acquired the dispute; later, as a second objective, set an analysis of the facts, focusing attention on the community organization that was created in the midst of the problem. For this, participant observation, news from newspaper, television reports as well as information, images and videos that were posted on the page of movement's Facebook and website YouTube, were used. Thus, the approach that tries to defend is, in order to understand why the conflict between the community actors and municipal authorities did emerged, it is necessary to exceed its most immediate cause which was the cuts in water supply, paying attention to other political, historical and socio-cultural variables.

Keywords: Conflict of water; collective actions; social movement; community organization; municipality.

\title{
Introducción ${ }^{1}$
}

El siguiente escrito presenta el análisis de un conflicto reciente por el agua generado durante el 2014 en el cantón de Barva de Heredia (Figura 1), cuando, en medio de constantes y largos recortes en el servicio de agua desde inicios del verano, surgió el grupo comunal llamado Foro Cantonal Barveño en Defensa del Agua (en adelante, Foro), el cual congregó a un considerable número de vecinos afectados que se manifestó en las sesiones del concejo municipal².

Dicha movilización se inserta dentro del contexto actual de aumento de la protesta comunal por el servicio de agua potable, donde las denuncias ante la Sala Constitucional lo convierten en el servicio público que más reclamos provoca, siendo la mayoría de estos entre el 2013 y 2014 (Fornaguera, 2015a). De acuerdo con un análisis realizado por Alpízar (2012), del 2000 al 2010 se han reportado ciento treinta y cuatro casos de conflictos por el agua en distintas comunidades del país, incrementándose de sobremanera a partir del 2008. Particularmente, en el 2014, dos casos de conflicto por el agua, aparte de Barva, tuvieron resonancia en los medios de comunicación: el de Paraíso de Cartago y el de Atenas y Grecia, en Alajuela (Gutiérrez, 2014; Fornaguera, 2014).

\footnotetext{
1 El siguiente trabajo forma parte de la tesis de licenciatura en Antropología Social llamada "Problemas en la capital del agua: el conflicto por el desabastecimiento de agua potable durante el 2014 en el cantón de Barva de Heredia", la cual se desarrolló con el apoyo de las becas de investigación del Instituto de Investigaciones Sociales de la Universidad de Costa Rica (IIS-UCR).

2 El concejo municipal es el órgano colegiado, deliberativo y autónomo que representa la máxima autoridad del municipio y que debe sesionar como mínimo una vez por semana. Está compuesto por regidores representantes de los partidos políticos que son de elección popular. En el caso de Barva, el concejo está compuesto por cinco regidores y sus respectivos suplentes, uno de los cuales funge como presidente municipal, encargándose de presidir y vigilar el orden de las sesiones, recibir las votaciones y conceder la palabra, entre otras (Unión Nacional de Gobiernos Locales, 2013).
} 


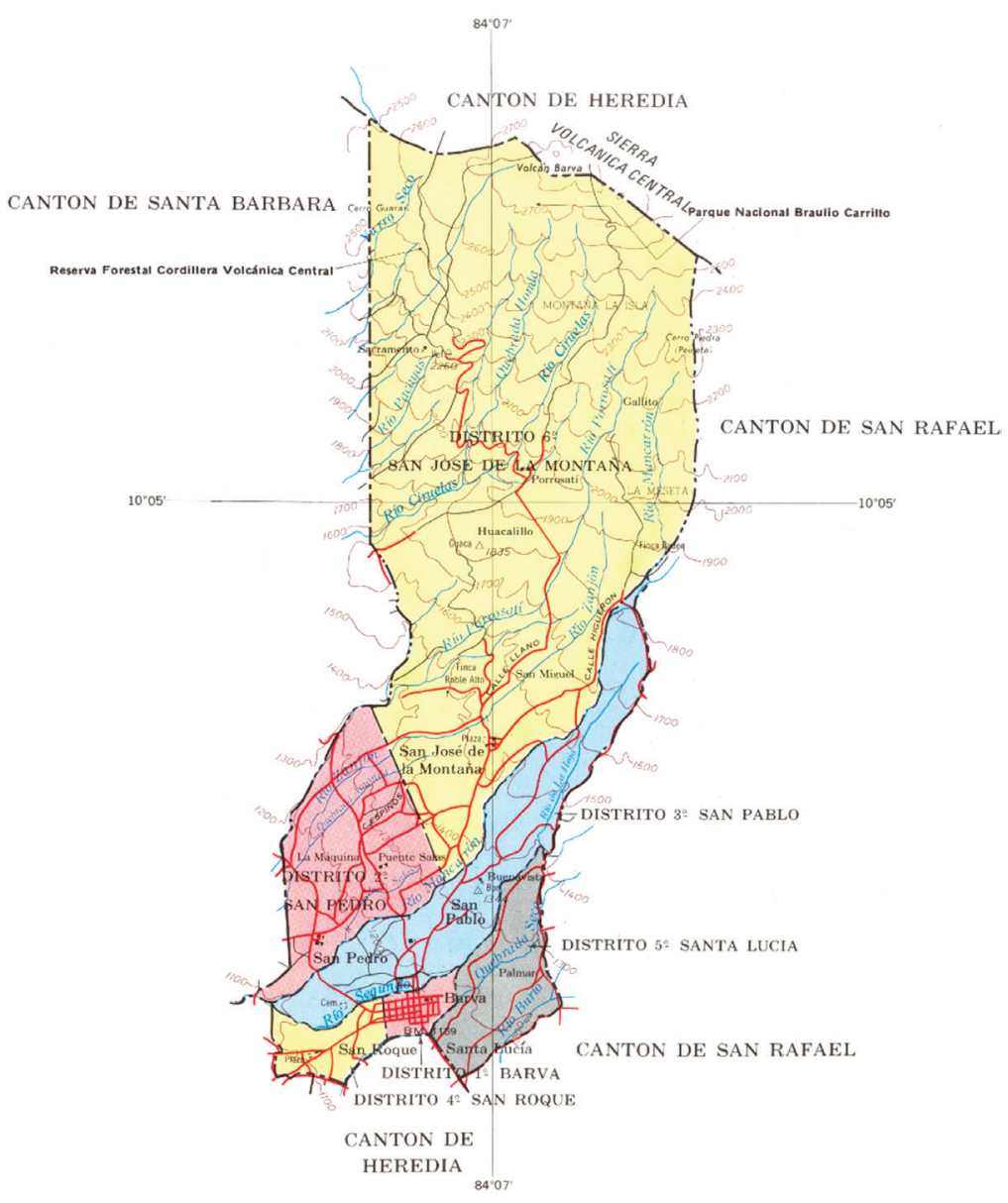

Figura 1: Mapa del cantón de Barva. Se ubica al norte del Valle Central, entre los cantones de Santa Bárbara, San Rafael y Heredia (Modificado de: http://ccp.ucr.ac.cr/bvp/mapoteca/CostaRica/generales/atlas_cantonal_1984/49-Barva.pdf).

El tema del agua en el país se ha encontrado en la palestra pública no solo por lo anterior, sino porque aún se encuentra en el plenario legislativo el proyecto de ley $n^{0} 17,742$ sobre la gestión integrada del recurso hídrico, el cual ha generado arduas discusiones entre distintos sectores sociales por tratarse de un proyecto que nació como iniciativa popular en el 2010 a partir de la recolección de firmas entre ciudadanos (Alpízar, 2012). Además, los distintos medios de comunicación han mostrado algunas carencias que tiene la administración del agua en el país, desde el Instituto Costarricense de Acueductos y Alcantarillados (AyA), cuya descoordinación ha llevado a que muchas comunidades sufran recortes de agua durante los veranos (Fallas y Agüero, 2014), hasta las Asociaciones Administradoras de Sistemas de Acueductos y Alcantarillados Sanitarios (Asadas), muchas de las cuales operan en la ilegalidad y cuya cantidad exacta es desconocida por el mismo AyA (Fornaguera, 2015b) .

3 Desde 1961, el AyA es el ente rector en materia de agua y saneamiento del país. Debido a la lejanía entre el Área Metropolitana, 
También, por el otro lado, están las municipalidades que aún administran los acueductos en sus cantones, las cuales han sido cuestionadas por la Contraloría General de la Republica, afirmando que de las veintiocho municipalidades que administran sus acueductos, el $69 \%$ carecía de información sobre la cantidad de agua que se extrae; mientras que la mayoría es deficiente en la planificación, inversión y uso de manuales de procedimientos para la administración y operación (Contraloría General de la Republica, 2014; Solano, 2014).

Precisamente, la Municipalidad de Barva forma parte de esos gobiernos locales que aún brindan el servicio de agua potable en sus jurisdicciones. Dicho ente provee del líquido a tres distritos del cantón a través de su acueducto municipal: Distrito Central de Barva, San Pablo y San Roque; con una población abastecida de aproximadamente 17400 personas ${ }^{4}$. Este acueducto se abastece de trece fuentes de manantial por gravedad, las cuales se ubican en su totalidad al norte del cantón, en el distrito de San José de la Montaña (con altitudes de entre los $1930 \mathrm{msnm}$ hasta los $2065 \mathrm{msnm}$ ), convergiendo en un mismo sistema de conducción que da un total de 9945 litros por segundo al acueducto. No obstante, en los aforos que ha hecho la municipalidad entre el 2010 y el 2013 en casi todas sus nacientes, se ha hecho palpable la disminución en el caudal de agua de estas, especialmente en los meses de verano (Federación de Municipalidades de Heredia, 2015).

Bajo ese marco general, este artículo se dividió en dos apartados, acorde con los dos objetivos. En primer lugar, se hizo una descripción del problema suscitado de mayo a diciembre del 2014, así como enero y febrero del 2015, ya que en ese período de tiempo es cuando se dan los principales acontecimientos de confrontación. Lo anterior con el fin de mostrar las características particulares que adquirió la contienda entre los llamados actores comunales, los cuales refieren a aquellos vecinos quienes participaron directa o indirectamente en la conformación del Foro, y las autoridades municipales, que hacen alusión a tres regidores del concejo municipal (uno de ellos es el presidente municipal) los cuales son afines al Partido Liberación Nacional (PLN), del que forma parte la alcaldesa. Asimismo, bajo esa denominación, cabe incluir a la ingeniera administradora del acueducto, la cual también fue responsabilizada por el problema 5 .

Dicha descripción es la base para el segundo objetivo en el apartado siguiente, el cual consistió en un

donde opera mayoritariamente esta institución, y las zonas rurales del país, se permitió que las comunidades que se organizaban podían gestionar su propia administración del servicio a través de la figura de la Asada, la cual debe ser previamente aprobada y periódicamente monitoreada por el AyA (Alpízar, 2012).

4Anteriormente se brindaba el servicio en los seis distritos del cantón. Sin embargo, a finales de la década de 1990 surge una separación entre los distritos de San Pedro y San José de la Montaña, cuando por serias deficiencias en la calidad y cantidad del agua servida en esos momentos, deciden formar su propia Asada con el aval de AyA. El caso del distrito de Santa Lucía fue similar en el mismo momento, pero debido a que varios vecinos solicitaron a la Municipalidad y al AyA que la administración del servicio pasara a manos de la ESPH S.A. (empresa público-privada que da el servicio de agua y electricidad en la provincia de Heredia), esta se ha encargado de proveer el servicio en todo el distrito desde entonces.

5 Mientras tanto, los dos restantes regidores se mostraron, desde el principio, contrarios a las medidas de la administración y afines a las demandas del Foro.

Cuadernos de Antropología 2016, 26(1), 63-84 / ISNN 2215-356X

http://revistas.ucr.ac.cr/index.php/antropologia 
análisis focalizado en la agrupación de actores comunales creado en medio del problema; es decir, en el Foro. Para ello, se partió de una corriente teórica de los movimientos sociales cercana al enfoque norteamericano de movilización de recursos, más específicamente, a la subescuela del proceso político o de las oportunidades políticas y a la subescuela de los procesos colectivos de interpretación. Incorporando cuatro dimensiones o recursos que, de acuerdo con Tarrow (1997), cuentan con actores movilizados: una estructura de oportunidades políticas, un repertorio de acción colectiva, una estructura organizativa y marcos de acción colectiva.

A través de ello, el fin que se persiguió fue defender la tesis de que para comprender a cabalidad la conflictividad por el agua en Barva, se debe sobrepasar la explicación meramente técnica-ingenieril de los recortes y prestarles atención a otras variables, entre las cuales están las políticas, históricas y socioculturales, las cuales desde las ciencias sociales es posible examinar.

\section{Metodología}

Metodológicamente hablando, se debe decir que, como residente desde varios años del cantón, fue posible ser testigo de los primeros acontecimientos de conflictividad de mayo a julio del 2014, sin que en ese momento se pensara en investigar el tema, hasta finales de agosto de ese mismo año, cuando formalmente se comenzó a construir el diseño de investigación para la tesis; por lo que se puede afirmar que el estudio del que se desprende este escrito comenzó con una participación observante y conversaciones informales, estas luego se transformaron, por un lado, en observación participante y, por el otro, en entrevistas semiestructuradas a ciertos actores clave, aunque no fueron incorporadas para este artículo.

Así, para la reconstrucción de los acontecimientos y análisis puntualizado acá, aparte de las observaciones realizadas en los meses de conflictividad, se trabajó con fuentes virtuales de prensa escrita y reportajes de algunos noticieros televisivos que informaron de este caso, debido a la notoriedad que en cierto momento adquirió la conflictividad a nivel de medios de comunicación.

Además, se contó con los volantes informativos que tanto la municipalidad como el Foro distribuyeron con sus versiones de la problemática. De igual forma, a nivel de redes virtuales, las publicaciones, imágenes y videos que el Foro Cantonal Barveño colocó en su página de Facebook ${ }^{6}$ fueron un material significativo; como también lo fueron cinco videos aficionados de personas quienes grabaron las sesiones municipales y algunas reuniones, colgadas en el portal de videos en internet YouTube.

Finalmente, la triangulación de datos para el análisis fue la reducción de la información recolectada por medio de la creación de una tabla cronológica, en la cual se fueron colocando por año, mes y día, los

6En la siguiente dirección: https://www.facebook.com/aguadebarva/?fref=ts 
principales acontecimientos de la contienda. Seguidamente, a partir de ella, se construyó un cuadro dividido en categorías analíticas basadas en los postulados teóricos con los que se trabajó.

\section{¿Qué ocurrió con el agua en Barva durante el 2014?}

Desde finales del 2013, algunos vecinos que formaban parte de la Asociación de Desarrollo de Barva pudieron conocer los resultados de un estudio de ingeniería forestal que alertaba sobre el mal estado de la zona cercana a las nacientes de agua pertenecientes al acueducto municipal. En dicho estudio, se mostraban imágenes del deterioro de la infraestructura del acueducto, lo cual generó un estado de alerta entre estos miembros y se acordó darle seguimiento al asunto ante la municipalidad.

Al iniciar el 2014, las autoridades meteorológicas advirtieron que ese iba a ser un año muy seco. Por esa razón, al igual que aconteció años atrás durante el verano, la municipalidad comenzó a aplicar recortes en el suministro del agua durante el día. No obstante, el pasar de los meses, aunado a la cantidad de horas en las cuales se cortaba el servicio (el rango entre los distintos sectores promediaba de las seis a las doce horas), hizo que un grupo de personas, descritas en el párrafo anterior, junto con representantes de otras asociaciones de desarrollo de los tres distritos afectados, acudieran el 5 de mayo al concejo municipal a presentar una carta de peticiones bajo el alegato de que los vecinos tenían el derecho a tener información confiable sobre lo que está pasando con el manejo del acueducto y su gestión financiera. A partir de ahí, se menciona la necesidad de conformar una Comisión Especial Municipal o Junta de Aguas

Por este motivo, un día después de recibida esa sesión del concejo, el presidente municipal invitó a las asociaciones de desarrollo y Asadas de otros distritos a participar en una reunión en las fechas siguientes con el fin de discutir el tema y ver las soluciones posibles desde el marco de acción del Código Municipal, a través de una Comisión de Aguas ${ }^{7}$. En las semanas posteriores continuaron reuniéndose por lo menos en tres ocasiones más.

Sin embargo, también se estaba organizando otro contingente de personas, el cual proponía una acción más confrontativa contra la municipalidad; este estaba conformado en su mayor parte por jóvenes quienes hacía unos meses estaban agrupados en torno a la campaña electoral con el partido político nacional, Frente Amplio (FA), en especial apoyando a José Ramírez, candidato a diputado por la provincia de Heredia ${ }^{8}$ Este

7 El Código Municipal es el instrumento normativo que por ley regula y detalla el régimen municipal costarricense. Entre las facultades que le concede este al concejo municipal en su artículo trece, inciso n), está la conformación de comisiones permanentes y especiales sobre distintos asuntos de interés comunal (Unión Nacional de Gobiernos Locales, 2013).

8 El FA es un partido que ideológicamente se ubica en la izquierda en el espectro político nacional. Fue fundado en el 2004 por José Merino del Rio, quien quedó electo como único diputado por la agrupación en el 2006. Para las elecciones del 2010 nuevamente lograrían un escaño en la Asamblea Legislativa por la provincia de San José con José María Villalta. 
grupo impulsó la creación de un foro de debate sobre el tema en el distrito de San Pablo para el día 17 de mayo (Figura 2), para lo cual acordaron, día antes, crear un grupo en Facebook que convocara al evento, bajo el nombre de Foro Cantonal Barveño en Defensa del Agua.

En ese momento, aún en medio de los mismos recortes de agua, comenzó a haber un reclamo por parte de los miembros del Foro por la actitud de la administración municipal de bloquear a las personas quienes preguntan o cuestionan sobre la situación en la página de Facebook de la Municipalidad (que posteriormente fue cerrada ante la cantidad de quejas de los vecinos); lo que fue interpretado por este grupo como una muestra de ocultamiento de información sobre la situación del acueducto.

Dicha circunstancia hizo que el Foro buscara una forma de presión más directa hacia la administración municipal, por lo que el sábado 24 de mayo se reunieron para discutir una idea que ya se venía comentando, la posibilidad de convocar a una movilización de protesta para la sesión municipal del concejo municipal del lunes 26 de mayo. Es así como en dicho día se realizó la primera convocatoria organizada por el Foro, donde llegó una cantidad de personas no esperadas, la cual llenó el salón municipal, que tiene una capacidad aproximada para sesenta personas. Un grupo de jóvenes del Foro cerró el paso de la calle que pasa al frente de la municipalidad, con el fin de que las personas, que no cabían en el salón, pudieran apersonarse en dicha calle.

Para esa sesión, los dirigentes del Foro llevaron dos petitorias concretas que exigían que fueran aprobadas por el concejo municipal. La primera era que se detuvieran los permisos de construcción y urbanos en los distritos que sufrían de problemas de agua; y la segunda, más controversial, era que se conformara una junta de expertos barveños (la cual luego será llamada Junta Interventora) que intervinieran el acueducto para que diagnosticaran y buscaran soluciones a la problemática.

Es a partir de ese momento cuando inicia una serie de disputas y choques entre ciertas autoridades municipales y los integrantes del Foro. Es decir, para ese momento fue posible ver la existencia de dos fuerzas de poder contrarias, cuya principal divergencia radicaba en la causa del problema del agua, ya que el punto concordante era que existía escasez del líquido para brindar el servicio de manera normal, pero, mientras que la municipalidad alegaba que ello se debía a fenómenos climáticos que hacían que no llegara agua a las nacientes, el Foro decía que más allá de ser un problema climático, el verdadero causante de la escasez ha sido la mala administración del acueducto en los últimos años.

En las sesiones municipales de los meses siguientes se dio una dinámica de disputas de poder, ya que si bien fue el Foro el que contó con el respaldo popular de muchos vecinos que también estaban molestos por la situación, las decisiones finales eran tomadas por las autoridades municipales, las cuales parecían no estar dispuestos a ceder su poder ante las peticiones y reclamos del Foro. Estos, como una forma de comunicar la situación a los vecinos, comenzaron a organizar reuniones en el parque central, al frente del edificio municipal, a las que llamaban cabildos abiertos, que luego se trasladaron a la Casa Comunal, perteneciente a la Asociación de Desarrollo de Barva. 


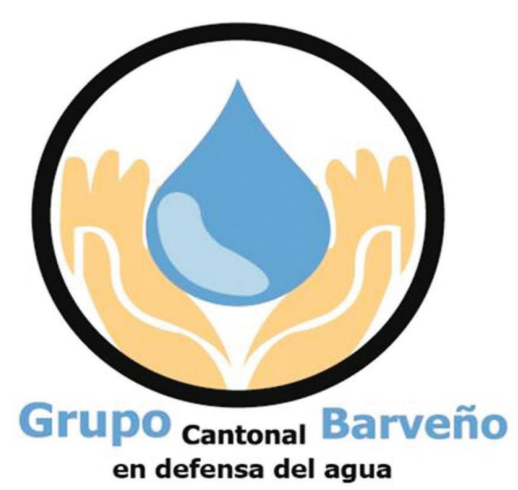

\section{Le invita al foro:}

\section{"La verdad sobre la situación del agua en el cantón de Barva"}

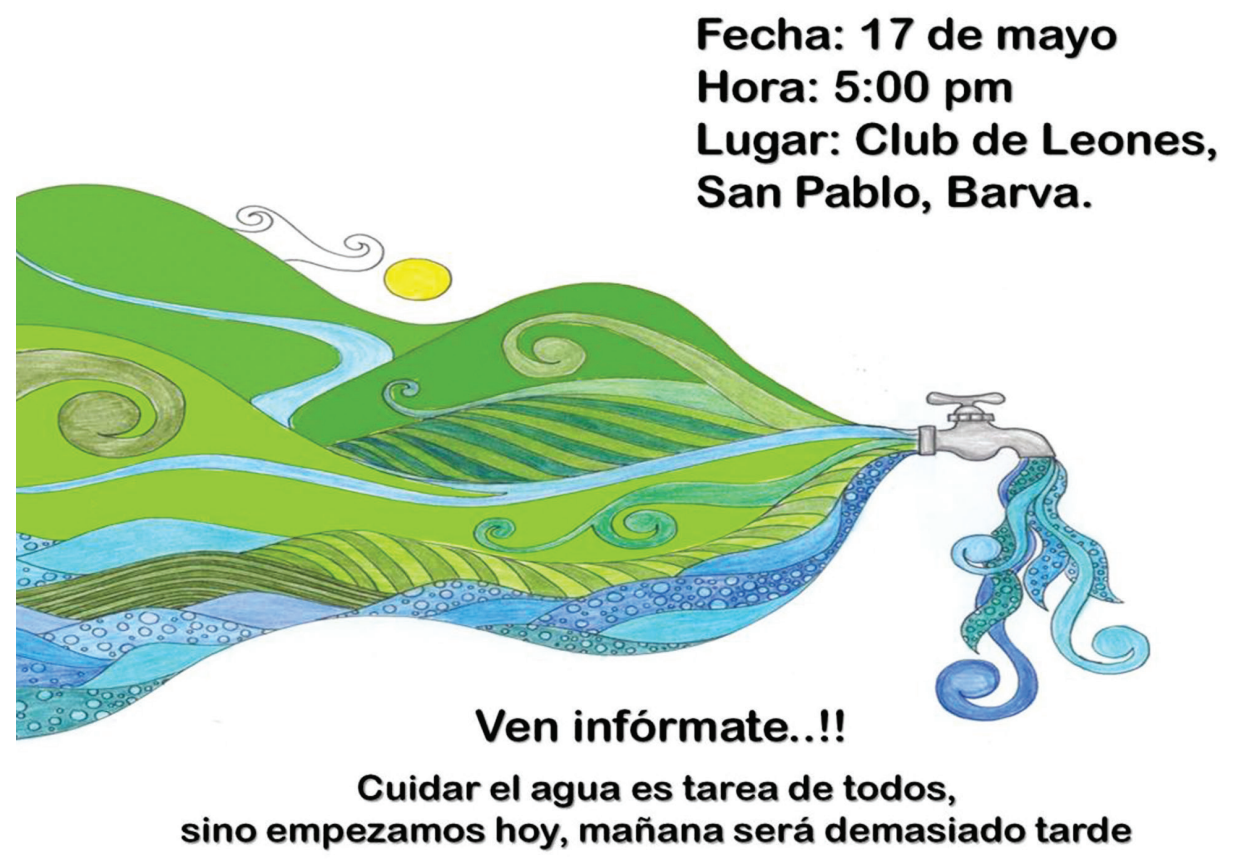

Figura 2: Afiche de convocatoria al foro de debate sobre la situación del acueducto del 17 de mayo del 2014 en el distrito de San Pablo (Fuente: https://www.facebook.com/aguadebarva/photos/a.1465448240359190.1073741828.1465430893694258/14 $67119310192083 /$ ?type $=3 \&$ theater). 
Con todo, la figura de junta Interventora fue finalmente aprobada y juramentada por el concejo municipal en junio (para que funcionara primeramente durante seis meses y luego se extendería a un año), momento cuando los recortes de agua comenzaron a mermar; y ya para julio el servicio volvió a su normalidad. Sin embargo, cuando pareció que el problema entre ambos bandos quedó atrás, a finales de julio el Foro hizo una nueva convocatoria a los vecinos para que se apersonaran nuevamente a las sesiones municipales, ya que se alertó de que la alcaldesa y demás autoridades municipales insistían en que la conformación de la junta era ilegal. Además, según el grupo, ella insistía en poner trabas al trabajo que la junta estaba intentando realizar sobre la situación del acueducto, y estaba tomando acuerdos sobre el tema sin consultarles. Ese llamado del Foro, como en las sesiones anteriores, volvió a tener eco entre los vecinos debido a la cantidad que se apersonó al salón municipal; pero ante la negativa del presidente municipal de conceder la palabra a uno de los presentes, la sesión se vio interrumpida por los gritos y ofensas que estos dirigían hacia ese personaje y demás autoridades municipales, por lo que se suspendió la sesión, no solo en esa ocasión, sino en la siguiente por la misma situación. Por este motivo, el Foro convocó a una marcha para la mañana del día domingo 3 de agosto por el distrito central (Figura 3), con el fin de que los vecinos se pronuncien en contra del autoritarismo y las trabas que ellos consideraban estaban poniendo las autoridades municipales.

Luego de ello, en los demás meses hubo regularidad en el servicio, pero los choques entre los dos bandos continuaban, ya no tanto en las sesiones municipales con los vecinos, sino en las discusiones que sobre la mesa se realizaban entre los miembros electos de la junta y la municipalidad. Sin embargo, en los primeros días de diciembre, los barveños y las barveñas se vieron afectados por nuevos recortes de agua, los cuales fueron intermitentes entre los distintos sectores por cerca de dos semanas. La municipalidad manifestó que la interrupción del líquido se debió a los fuertes vientos que azotaron el Valle Central en esos días, esto provocó que algunas ramas rompieran parte de la tubería madre. Al contrario, el Foro señalaba que no era solo una consecuencia de un elemento climático, sino que, si efectivamente una rama rompió un tubo, fue porque la infraestructura del acueducto era ineficiente y revelaba el descuido con que se ha dejado a este por parte de la municipalidad.

Cuando el abastecimiento de agua se había estabilizado, después del problema de la ruptura del tubo, la municipalidad hizo un anuncio por perifoneo sobre un nuevo recorte en el servicio de agua para el día 23 de diciembre, fecha cuando la institución, como el resto de entes estatales, cesaban funciones como parte de las vacaciones de fin de año. La razón del recorte fue un trabajo que la entidad contrató a una empresa privada, y consistía en revisar y calibrar las válvulas de presión e instalar un macromedidor; no obstante," según el Foro, nunca se le consultó a la Junta sobre este trabajo. En este la municipalidad tenía previsto que la interrupción del servicio no iba a pasar de un día, pero problemas técnicos al momento de la instalación hicieron que el día 24 de diciembre muchos sectores amanecieran sin agua, lo que volvió a generar malestar entre los habitantes. De esta forma, se convocó a una reunión de emergencia en horas de la tarde, primero en el parque central y luego en la casa comunal, para decidir si se iba a tomar algún acción disruptiva ante el problema, pero la idea de cerrar una de las vías principales no tuvo eco entre los presentes, en parte porque al terminar la tarde el suministro comenzó a volver a las casas. 




Figura 3: Afiche de convocatoria del Foro a la marcha del 3 de agosto del 2014 (Tomado de: https://www.facebook.com/aguadebarva/photos/a.1466104286960252.1073741829.1465430893694258/1499597246944289/?type=3\&theater).

A partir de este hecho se decidió volver a convocar a los vecinos para la primera sesión municipal del 2015. Esta tuvo lugar el 5 de enero y, como en otras ocasiones, varios vecinos acudieron al llamado, por lo que nuevamente algunos jóvenes cerraron la calle principal que pasa al frente del edificio municipal, y había algunos medios de comunicación cubriendo la sesión. Esta fue suspendida cuando, luego de un par de horas, los ánimos se caldearon entre la alcaldesa y algunos presentes, quienes la emplazaron insistentemente desde que llegó. El asunto derivó en un intercambio de palabras con un par de dirigentes de la junta y el Foro en relación con los últimos hechos acontecidos en diciembre. 
Justo al día siguiente, desde la mañana, comenzó a llegar el agua sucia a las casas ${ }^{9}$, mientras que en otros sectores se cortó del todo el suministro por algunas horas. La explicación dada por la municipalidad fue que, al igual como pasó en diciembre, los fuertes vientos de esos días provocaron que unos árboles se cayeran y rompieran parte de la tubería, y contaminaran el agua con barro. Si bien miembros del Foro confirmaron lo anterior, nuevamente atribuyeron el problema a la mala infraestructura del acueducto, donde la municipalidad no había tomado medidas preventivas contre este tipo de situaciones ambientales..

A pesar de esos dos hechos, durante el verano del 2015 no hubo recortes de agua, por lo que el Foro no volvió a hacer convocatorias a los vecinos a las sesiones municipales para los siguientes meses. En paralelo, las acciones y publicaciones en las redes sociales hechas por el Foro cada vez fueron menos. Su última convocatoria a una sesión municipal fue a finales de julio y la junta debía presentar el informe final de labores al cumplirse el año por el cual fue juramentada. No obstante, a diferencia del año anterior, en esta ocasión el salón municipal se encontraba prácticamente vacío.

\section{¿Cómo interpretar los acontecimientos ocurridos en Barva?}

Luego de haber expuesto, a grosso modo, los principales sucesos que tuvieron lugar en este cantón en relación con el problema del agua, es hora de poder brindar un análisis de estos según algunas posturas teóricas.

En primer lugar, se entiende que cuando los sujetos que protestan o luchan lo hacen de manera conjunta, con cierto grado de organización y coordinación, trascienden el aislamiento individual para constituirse en un actor colectivo "que busca promover un cambio social favorable a los intereses de sus miembros $\mathrm{u}$ oponerse a un cambio que los afecta" (Serra, 2003, p. 25); esa colectividad supone que los individuos comparten algo en común (Chihu, 1999).

Así, más allá de un factor de escala o tamaño, es posible decir que un movimiento social es un tipo de acción colectiva que está conformada por una agrupación de personas quienes comparten objetivos, solidaridad y una identidad común, que en el planteamiento de desafíos colectivos de cambio social mantienen una interacción con las elites, los oponentes y las autoridades, lo que lleva a una reorganización o cambios en la distribución del poder ${ }^{10}$.

9 Que se le llamó "el agua de tamarindo", debido al color café con que llegó a las casas.

10 Es necesario aclarar que en este trabajo no se debate si este grupo creado en Barva durante el 2014 se le puede llamar o no movimiento social, dado que tuvo un carácter local concreto de ciertos distritos, no a nivel nacional, condición que algunos consideran necesaria para denominarlo de esa manera. En su lugar, se pretende utilizar las aproximaciones teóricas que se han 
Como forma de organizar el análisis, se sigue el planteamiento de Tarrow (1997) al decir que un movimiento social tiene a su disposición cuatro recursos: a) una estructura de oportunidades políticas, b) un repertorio de acción colectiva, c) una estructura organizativa y d) marcos de acción colectiva.

\section{a) Estructura de oportunidades políticas}

El concepto de oportunidades políticas busca conocer el cuándo de la formación del movimiento, ayudándonos a comprender las razones de por qué los "movimientos adquieren en ocasiones una sorprendente, aunque transitoria, capacidad de presión contra las elites y luego la pierden rápidamente a pesar de todos los esfuerzos" (Tarrow, 1997, p. 156). Para McAdam (s/f., citado por Berrío, 2006), el concepto busca explicar dos variables dependientes: el punto temporal en el que surge la acción colectiva y los resultados obtenidos por el movimiento.

El movimiento generado en Barva ocurrió, como se ha señalado, en el 2014, un año electoral que presentó ciertas rupturas con el espectro político de años anteriores. Por un lado, se hace referencia al desgaste que el partido oficialista había tenido luego de dos mandatos presidenciales seguidos, con Johnny Araya como un candidato presidencial cuestionado por algunos sectores sociales, y que parecía generar desconfianza en cierta parte del electorado y del mismo partido (Oviedo, 2013) ${ }^{11}$. Por otro lado, de manera conjunta, había una percepción generalizada en los sondeos de opinión de que ya era necesario un cambio político.

Todo esto conllevó a dos resultados: primero, el FA con la figura de José María Villalta adquiere un creciente apoyo en los cuatro meses previos a las elecciones, y logra finalmente colocar un total de nueve diputados en la Asamblea Legislativa, algo que hasta ese momento era inesperado para un partido de izquierda en el país. Segundo, la derrota en las urnas que el Partido Acción Ciudadana (PAC) le proporcionó al PLN hizo que las estructuras oligárquicas de este último sufrieran una división, en especial a raíz de la renuncia de Araya, y el partido viera en peligro su autoridad y prestigio (Chacón, 2015; Ruiz, 2014) ${ }^{12}$. Con

manejado para el estudio de los movimientos sociales y contrastarlos con el caso de estudio. Para una mayor profundización del concepto de movimientos sociales utilizado acá, ver Pérez (1994), Raschke (1994), Munck (1995), Castells (2012), Tarrow (1997), Serra (2013), Melucci (s/f., citado por Svampa, 2009) y Tilly (1984, citado por Tarrow, 1997).

11 Nos referimos al PLN. Desde su fundación, en 1951, esta agrupación política ha logrado convertirse en el partido político más representativo del país, alcanzando la Presidencia de la República en nueve ocasiones, de las cuales las últimas dos correspondieron a Oscar Arias (2006-2010) y Laura Chinchilla (2010-2014). De igual forma, Johnny Araya había sido alcalde de la Municipalidad de San José entre 1998 y 2013, antes de convertirse en el candidato oficial de dicho partido.

12 Debido a que en la primera ronda de las elecciones nacionales del 2 de febrero ninguno de los partidos participantes por la Presidencia alcanzó el $40 \%$ de votos válidos exigidos por el Tribunal Supremo de Elecciones, el 6 de abril se llevó a cabo la segunda ronda entre el PAC y el PLN, como los dos partidos que alcanzaron más votos en primera ronda. El PAC obtuvo un 77,9 $\%$ de los votos, mientras que el PLN únicamente el 22,1\%. Sin embargo, en medio de ambas votaciones, el 5 de marzo, Johnny Araya anunció que se retiraba de la contienda, aceptando la eminente derrota que le proporcionaría el candidato del PAC, y actual presidente de la República, Luis Guillermo Solís.

Cuadernos de Antropología 2016, 26(1), 63-84 / ISNN 2215-356X

http://revistas.ucr.ac.cr/index.php/antropologia 
lo anterior hacemos referencia a dos variables dentro de las oportunidades políticas: las inestabilidades de los alineamientos políticos y la división de las elites (Brunet y Pizzi, 2010).

La variable que más interesa destacar en esta coyuntura tiene que ver con lo que se le ha llamado la disponibilidad de aliados influyentes, esta refiere a "la existencia de vínculos entre las personas movilizadas y ciertos miembros del cuerpo político o estatal" (Brunet y Pizzi, 2010, p. 31) que pueden ofrecer una mayor probabilidad de éxito a los movimientos. En este caso, el peso recae en una figura, José Ramírez, otrora regidor de la Municipalidad de Barva en el periodo 2010-2013 antes de ser candidato a diputado por Heredia en el 2014 con el FA, puesto que finalmente lograría. Este personaje anteriormente había participado en luchas con los miembros dirigentes del Foro, siendo la más recordada la oposición al Proyecto Turístico Volcán Barva entre el 2006 y el 2008, aproximadamente ${ }^{13}$.

Ahora como diputado en la Asamblea Legislativa, el rol de Ramírez pasaría a ser la de "padrino político" del movimiento. Su candidatura a diputado no solo permitió que se agruparan varios simpatizantes del FA, que como se dijo al inicio fue un factor determinante en el nacimiento del Foro, sino que, una vez en su puesto, denunció desde su estrado en la Asamblea a la administración municipal por el problema con el agua, y defendió el movimiento organizado, al dar incluso declaraciones en la prensa sobre el tema (Grajales, 2014). Este acompañó al Foro en un par de sesiones municipales, en la marcha de agosto ${ }^{14}$ y en algunos cabildos efectuados. Así los hechos,donde es más claro este rol de aliado del movimiento fue cuando invitó al inicio del conflicto a dos dirigentes del Foro a una conferencia de prensa en la Asamblea para que se refirieran al problema de Barva.

\section{b) Repertorio de acción colectiva}

Luego están los repertorios de acción colectiva; esto constituye un recurso que facilita la movilización, haciendo referencia a "modos recurrentes de acción colectiva que llevan a cabo los movimientos sociales, y que constituyen productos culturales aprendidos que surgen y cobran forma a partir de confrontaciones anteriores" (Brunet y Pizzi, 2010, p. 32).

Así, el repertorio del Foro se constituyó principalmente en la vía institucional, es decir, por las acciones colectivas que funcionan a manera de "licencia social" (Svampa, 2008); principalmente por medio de la figura legal de los concejos municipales, como se indicó en páginas anteriores. El Foro convocaba a los vecinos cada vez que iba a haber sesión del concejo, con el fin de hacer presión ante este órgano para que se aprobaran sus demandas. Dado que la administración municipal contaba con mayoría en las votaciones

13 Más adelante se hará mención a este.

14 Más adelante se hará mención a esta.

Cuadernos de Antropología 2016, 26(1), 63-84 / ISNN 2215-356X

http://revistas.ucr.ac.cr/index.php/antropologia 
del concejo, no siempre el movimiento pudo lograr que sus petitorias fueran acatadas, al apelar a otras vías institucionales, como la presentación de cartas a la misma administración municipal y a otras instituciones públicas, como AyA, el Ministerio de Salud, la Defensoría de los Habitantes, o enviar comunicados de prensa a los distintos medios y dar entrevistas en programas radiales y noticieros televisivos.

Acompañando a las medidas anteriores, también hubo momentos de acción colectiva disruptiva, en las cuales una de las más destacables fue el cierre de la calle principal ubicada al frente de la municipalidad, este se hacía cada vez que había convocatorias masivas a las sesiones del concejo. No deja de ser relevante que en esos casos los encargados de cerrar la calle -con una manta larga de cerca de cinco metros- eran los integrantes más jóvenes del Foro.

Otra acción disruptiva fue la llamada marcha por la defensa del agua y respeto al pueblo barveño, organizada en el primer domingo de agosto del 2014. Esta se dio luego de que el Foro reclamara que la alcaldesa insistía en anular por la vía legal la creación de la junta, al poner trabas a la labor que esta intentaba realizar.

Destacan como formas de deliberación las reuniones o cabildos abiertos (no oficializados por la municipalidad $)^{15}$ que los dirigentes del Foro realizaron en el parque central, con el fin de exponer a los vecinos la situación del problema del agua, así como las acciones que ellos estaban ejecutando y la proyección de videos preparada por ellos mismos.

Tampoco hay que dejar de mencionar el reparto de volantes informativos casa por casa que durante varios meses estuvo haciendo el Foro durante las mañanas y tardes de los fines de semana en los tres distritos afectados (nuevamente esta labor recayó en los integrantes más jóvenes). En algunas ocasiones se pagó el servicio de perifoneo por las calles del cantón, a fin de informar sobre la situación del acueducto. Todos esos gastos fueron costeados por los mismos miembros del Foro, y una forma de obtener ingresos económicos fue a través de la venta de camisetas blancas con el logo del Foro, las cuales, a juzgar por la cantidad de personas que las usaban, tuvieron buena aceptación entre los vecinos.

\section{c) Estructura organizativa}

El tercer recurso por considerar lo constituye la estructura organizativa; o lo que es igual, las redes sociales que están tejidas en torno a los actores que fundan y conforman el movimiento. Con esto se hace referencia a que las relaciones pre-existentes mantenidas por los fundadores o líderes tienen un peso muy

15 Lo anterior debido a que la figura oficial del cabildo se desprende del artículo cuarto, inciso g), del Código Municipal, entendiéndola como una consulta popular que el concejo municipal debe aprobar en la cual se invita a los habitantes a discutir asuntos de interés para la comunidad (Unión Nacional de Gobiernos Locales, 2013).

Cuadernos de Antropología 2016, 26(1), 63-84 / ISNN 2215-356X

http://revistas.ucr.ac.cr/index.php/antropologia 
importante en la incorporación de nuevos individuos que ensanchan el tamaño del movimiento, ya que estas redes sociales ayudan a reducir los llamados "costos sociales transaccionales de la convocatoria de manifestaciones, y mantiene unidos a los participantes, incluso una vez que el entusiasmo inicial de la confrontación se ha desvanecido" (Tarrow, 1997, p. 56).

De esta manera, se plantea que el principal factor que más incidió en el éxito de la organización inicial del Foro es que sus fundadores o líderes ya habían tenido una experiencia previa como actor colectivo cuando, entre el 2006 y 2008, se organizó el llamado Movimiento Regional por la Defensa de las Montañas del Norte de Heredia ${ }^{16}$. Si bien esta agrupación no fue exclusivamente barveña, dado que estaba conformada por personas pertenecientes a los cantones que según ellos se iban a ver afectados por este proyecto turístico, sí se puede decir que tuvo como locus del conflicto al cantón de Barva, dado que la jurisdicción territorial del proyecto era de este territorio, además que le correspondía a esta municipalidad aprobar o rechazar el proyecto ${ }^{17}$.

De esa experiencia organizativa se pueden identificar cinco dirigentes del actual Foro que estuvieron en la dirección de aquel movimiento, incluyendo al diputado Ramírez. En términos de una pirámide organizativa, se puede decir que estos personajes son los líderes del movimiento; seguido de las bases, personas colaboradoras en la creación del Foro, que tal vez era la primera vez que se integran al tema del agua en el cantón (en especial los jóvenes) o tenían una menor dedicación de tiempo al tema. Además, en el tercer nivel estaban los simpatizantes, es decir, aquel contingente de vecinos que acudían a los llamados del Foro, apoyándolo en sus acciones, pero que tenían una participación e involucramiento muy intermitente.

También hay que destacar que con la disposición de herramientas digitales (como Dropbox, YouTube, Facebook y WhatsApp), la comunicación entre los mismos miembros de la estructura organizativa, así como de estos con el resto de vecinos, se facilitó mucho más; ya que como lo dicen Tilly y Wood (2009), los participantes de las movilizaciones de este siglo han integrado las nuevas tecnologías en sus organizaciones, en tanto les permite aumentar el ámbito geográfico que anteriormente podía cubrir un movimiento social.

16El movimiento nació como oposición al proyecto turístico volcán Barva, este consistía en aumentar la cantidad de visitantes que llegaban al sector del volcán Barva del parque nacional Braulio Carrillo, para lo cual proponía la ampliación de las rutas de acceso, así como la construcción de infraestructura de atracción turística dentro del parque nacional. Luego de evitar que el proyecto se llevara a cabo, dicha agrupación se desintegró.

17 Vale decir al respecto que la alcaldesa de ese momento era la misma para cuando surgió el conflicto del 2014, ya que fue electa por primera vez en el 2006 por un periodo de cuatro años, pero en el 2010 logró la relección para un periodo de seis años más. Además, ella era una de las que apoyaba dicho proyecto en sus inicios; probablemente porque uno de sus proponentes era diputado de la provincia de Heredia por el PLN. 


\section{d) Marcos de acción colectiva}

El último recurso por mencionar está relacionado con los marcos de significación, los cuales fueron retomados y reinterpretados al conjunto de creencias y significados orientados a la acción y legitiman las actividades de un movimiento (Chihu, 2006). En términos generales, se puede hablar de que un colectivo desarrolla un proceso de enmarcado a través del discurso como un esfuerzo estratégico para propiciar, motivar y legitimar la acción colectiva. Dentro de este proceso, y siguiendo el planteamiento que han desarrollado especialmente Hunt, Benford y Snow (2006), podemos citar tres tipos de marcos que se encuentran interrelacionados: 1) un marco de diagnóstico, 2) un marco de pronóstico y 3) un marco de movilización.

1) El marco de diagnóstico identifica las situaciones consideradas como problemáticas o injustas que son por las cuales se lucha, así como también a los actores responsables de haber causado dichas situaciones (Hunt, Benford y Snow, 2006).

Desde que se hizo la primera convocatoria, el Foro planteó que la raíz del problema recaía en una mala administración del acueducto, donde en las últimas dos administraciones se han dado negligentemente permisos para el desarrollo de fraccionamientos, condominios y urbanizaciones, a pesar de que se carece de un plan regulador urbano. Además de que ha dejado de invertir presupuesto en el acueducto, descuidando incluso las concesiones que tenían de otras nacientes, llevándolo a esa situación problemática.

2) El marco de pronóstico es una especie de complemento del anterior, ya que en este se establece un plan para corregir la situación que se considera problemática, "especificando para ello qué debería hacerse y quién tendría que hacerlo, es decir: los objetivos específicos, las tácticas y estrategias a seguir" (Hunt, Benford y Snow, 2006, p. 164).

Para el Foro, la solución inmediata que se necesitaba era la intervención de la administración del acueducto, por medio de la participación de vecinos que durante muchos años han estado cercanos al manejo del acueducto. Una vez alcanzado lo anterior, se debían suspender los permisos de construcción en los distritos afectados hasta que no se hubiese estabilizado la problemática de abastecimiento. Así mismo, se debía realizar una visita a las nacientes para evaluar de primera mano el estado de la infraestructura y el caudal de agua con que se encontraban estas en ese momento. Por último, para cerrar con las acciones en el corto plazo, proponían elaborar un plan de contingencia, el cual constaría de acciones concretas tendientes a evitar que el siguiente verano del 2015 se sufriera los mismos problemas de desabastecimiento. 
Al mediano y largo plazo, hablaban de poder financiar un estudio de capacidad y optimización del acueducto, el cual era necesario antes de pensar en la excavación de un nuevo pozo o tanque de almacenamiento para el acueducto, como lo sostenían las autoridades municipales.

3) No obstante, estos autores afirman que, aunque se haya identificado el problema, sus responsables y las soluciones para resolverlo, esto no es suficiente para lograr la participación de personas en un movimiento; por lo que es necesaria la construcción de un marco de motivos que alienten la participación a través de un vocabulario de movilización adecuado y un acervo cultural compartido, que justifique la acción por la que se lucha (Hunt, Benford y Snow, 2006).

Uno de los argumentos empleados por el Foro en las convocatorias para alentar la participación del resto de vecinos afectados fue la referencia a estos como "el pueblo", donde este era el encargado de decidir: "El pueblo el que ha decidido, no es una voluntad nuestra, somos simples soldados y si tenemos que ir como soldados ahí estamos" (Facebook Grupo Cantonal Barveño en Defensa del Agua, 9 de junio del 2014). Por ello, algunas de las principales palabras utilizadas cuando invitaban a las sesiones municipales o a los cabildos abiertos eran "lucha", "derechos" y "participación ciudadana".

Asimismo, el Foro interpretaba los acontecimientos como un golpe a la democracia, en el sentido en que las autoridades municipales tomaban decisiones sin tomar en consideración la participación de los habitantes. Cuando en una de las sesiones municipales de principios de junio del 2014, suspendida por los gritos y bullicio de parte de los vecinos presentes, las autoridades municipales salieron por un hueco en la pared (que comunicaba al comedor de la municipalidad, el cual se había hecho como salida de emergencia ante una posible amenaza de violencia física ante la presión de los vecinos en esos momentos), el Foro manifestó que ese día se rompió la "democracia local barveña”; cuestionando, además, que con ello la alcaldesa le huía al pueblo y a los cuestionamientos que tenían derecho de hacer.

Ahora bien, quizás el principal motivo que la agrupación utilizó para movilizar a los vecinos fue la clara llamada de atención a que si no se participa en la solución del problema el próximo verano, se sufriría una crisis de desabastecimiento más grave. Aunque fue posible escuchar dicho argumento una vez que el servicio de agua se había estabilizado, con esto se buscaba el compromiso de los vecinos con base en la experiencia padecida. Por ejemplo, en un volante informativo repartido casa por casa a finales de diciembre del 2014, que tenía como finalidad invitar a la primera sesión municipal del año siguiente, el Foro hizo especial énfasis del problema de la falta de agua del 24 de diciembre: 
Los responsables de que los días de fiesta de la navidad se cubrieran de angustia y zozobra deben RENUNCIAR E IRSE PARA SUS CASAS Y DEBEN SER CASTIGADOS. Que se detenga la irresponsabilidad, la improvisación y las ocurrencias. Basta de jugar con los recursos de todos y todas (Facebook Grupo Cantonal Barveño en Defensa del Agua, 27 de diciembre del 2014. Mayúsculas en el original).

Igualmente, para convocar a una sesión municipal en enero del 2015 donde se expondría el plan de contingencia que dos miembros de la Junta elaboraron para la municipalidad, apelaron a las experiencias con los recortes de agua del año anterior:

Recuerda usted el verano pasado? Los días enteros sin agua para cocinar, para limpiar, sin agua para bañarse antes de ir al trabajo?

Recuerda usted el pasado 23 y 24 de diciembre? Los tamales a medio hacer? Recuerda el agua de tamarindo? (Facebook Grupo Cantonal Barveño en Defensa del Agua, 14 de enero del 2015).

Por último, no se puede dejar de referir un acervo cultural simbólico que el Foro utilizó como parte del proceso de enmarcado, el cual fue la música de una cimarrona ${ }^{18}$. Específicamente, esta tocó en dos ocasiones entre mayo y junio del 2014 en la calle al frente del edificio municipal donde se encontraban aglomerados los miembros del Foro y los vecinos que se hicieron presentes a la sesión municipal. Lo que resalta de ello es que la cimarrona fuera usada en dos sesiones que se consideraron como un triunfo del movimiento, debido a las petitorias que en ese momento el concejo municipal aprobó. La otra ocasión en que se hizo presente la cimarrona fue en la marcha organizada en agosto. Dado el fuerte arraigo histórico y cultural mantenido por los habitantes del cantón de Barva con la música de cimarrona, se puede decir que su uso en estos contextos buscaba generar un sentido de identidad entorno a un elemento cultural común -o por lo menos reconocido- para los habitantes.

18 La cimarrona es una agrupación de músicos (generalmente jóvenes, entre cuatro a siete miembros) con instrumentos de viento y percusión que se encargan de tocar canciones tradicionales costarricenses o adaptaciones de canciones con ritmos movidos como la cumbia, el merengue, el swing criollo, entre otros. Barva ha sido uno de los focos en el país donde más ha perdurado la tradición de la cimarrona, en especial asociada a las mascaradas, cuya celebración se da en el distrito central, en agosto, con las fiestas patronales de San Bartolomé, asimismo cada distrito posee también su propio patrono y fecha de celebración. Por tal motivo, en todo el cantón es posible encontrar varios grupos dedicados a la música de cimarrona. Para mayor detalle sobre una de estas celebraciones patronales ver González (2014). 


\section{Conclusiones}

En este artículo se ha realizado un análisis del conflicto por el agua generado en el cantón de Barva durante el 2014. Para ello, se detalló primeramente el problema del desabastecimiento en servicio del líquido, y seguidamente se hizo un análisis del conflicto, centrándose en el llamado Foro Cantonal Barveño en Defensa del Agua, el cual fue un grupo de vecinos que se creó como catalizador del descontento en contra de las autoridades municipales, a las que se culpó por el problema.

El planteamiento defendido en estas páginas es que para poder entender por qué surgió el conflicto entre los actores comunales y las autoridades municipales, hay que sobrepasar su causa más inmediata que fueron los recortes en el suministro de agua. Es decir, se reconoce que estos recortes fueron el principal motivo por el cual hubo un descontento entre los habitantes que se externó a través de la creación del Foro, confirmando la centralidad que tienen las reivindicaciones materiales como el aspecto más importante para la movilización entre los participantes (Edelman, 2005), pero reconociendo que es necesario prestarles atención a otras variables políticas, históricas y socioculturales que giran en torno a esta conflictividad.

En ese sentido, se propuso que para el momento cuando se da el desabastecimiento de agua en Barva, hay una serie de cambios en el espectro político nacional que permiten la existencia de una base organizativa en el cantón, la cual incluía a antiguos dirigentes de luchas anteriores y a un grupo considerable de jóvenes, esta fue reactivada ante el problema del agua; contando con el aliciente de que uno de esos antiguos activistas era investido de un nuevo poder político al ser electo diputado, convirtiéndose así en "padrino político" del movimiento. Asimismo, una vez que la estructura organizativa fue reactivada, esta pudo ensancharse a través de sus redes sociales (tanto las referidas a los lazos sociales, como a las digitales, específicamente Facebook), así como también por los marcos de acción colectiva que construyó con sus discursos de movilización. Esto le permitió contar con una mayor fuerza social para realizar de manera exitosa una serie de acciones colectivas, mayoritariamente institucionales y algunas veces disruptivas, acordes con sus objetivos.

No se quiere cerrar este trabajo sin mencionar la importancia de prestarles atención a las maneras de reconfiguración que traen consigo ciertas conflictividades ambientales en las comunidades, como por ejemplo en el ámbito político. Precisamente, siguiendo lo anterior, parece ser que la problemática del agua en Barva fue una variable que influyó en los recientes resultados de las elecciones municipales ${ }^{19}$; lo que

19 Nos referimos a las elecciones municipales del 7 de febrero del 2016; y en especial en dos de los distritos afectados por la crisis de agua (Barva y San Pablo), donde el FA le sacó una amplia diferencia en votos al PLN para el puesto de alcaldía, lo que finalmente llevó a que el cantón de Barva tenga la primera y única municipalidad del país que va a ser administrada por un candidato del FA. 
permitiría reforzar la afirmación de que los movimientos sociales no solo son receptores pasivos de las oportunidades políticas, sino que ellos mismos crean también sus propias oportunidades políticas; pero eso es tema para otra discusión.

\section{Referencias bibliográficas}

Alpízar, F. (2012). ¿Democracia ecológica? Las instituciones, la participación política y las contiendas por el agua en Costa Rica (1821-2010) (Tesis de doctorado inédita). Universidad Complutense de Madrid, Madrid, España.

Berrío, A. (2006). La perspectiva de los nuevos movimientos sociales en las obras de Sidney Tarrow, Alain Touraine y Alberto Melucci. Estudios Políticos, 29, 219-236. Recuperado de http://www.redalyc.org/ articulo.oa?id=16429057009

Brunet, I. y Pizzi, A. (2010). La acción colectiva desde la teoría de la movilización de recursos. Sociedad y Utopia, 36, 27-38. Recuperado de http://www.sociedadyutopia.es/images/revistas/36/EstudiosAccionColectiva.pdf

Castells, M. (2012). Redes de indignación y esperanza. Los movimientos sociales en la era de internet. Madrid: Alianza Editorial.

Chacón, V. (30 de setiembre de 2015). PLN buscará mantener su poder en alcaldías en elecciones del 2016. Semanario Universidad. Recuperado de http://semanariouniversidad.ucr.cr/pais/pln-buscara-mantener-su-poder-en-alcaldias-en-elecciones-del-2016/

Chihu, A. (1999). Nuevos movimientos sociales e identidades colectivas. Iztapalapa, 47, 59-70. Recuperado de http://tesiuami.uam.mx/revistasuam/iztapalapa/include/getdoc.php?id=622\&article $=634 \& \mathrm{~m}$ ode $=$ pdf

Chihu, A. (2006). El análisis de los marcos en la sociología de los movimientos sociales. México D.F.: Universidad Autónoma Metropolitana-Miguel Ángel Porrúa.

Contraloría General de la República. (2014). Informe de auditoría de carácter especial sobre la gestión de los acueductos municipales. San José: Contraloría General de la República. Informe $\mathrm{n}^{\circ}$ DFOE-DLIF-1-2014. Recuperado de http://www.asamblea.go.cr/Informes_de_la_Contraloria/Informes $\% 20$ 2014/c-\%20informes_marzo_2014/DFOE-DL-IF-1-2014.pdf

Edelman, M. (2005). Campesinos contra la globalización. Movimientos sociales rurales en Costa Rica. San José: Editorial de la Universidad de Costa Rica.

Fallas, H. y Agüero, M. (10 de junio de 2014). Ineficiencia del AyA tiene al Valle Central a secas. La Nación. Recuperado de http://www.nacion.com/data/Ineficacia-AyA-Valle-Central-secas_0_1419858052. html 
Federación de Municipalidades de Heredia. (2015). Plan de Contingencia para la estabilización del acueducto municipal en la atención de los bajos niveles hídricos del cantón de Barva. Heredia: Federación de Municipalidades de Heredia. Manuscrito inédito.

Fornaguera, I. (20 de setiembre de 2014). Lio por agua tiene a Grecia y Atenas enfrentados. La Nación. Recuperado de http://www.nacion.com/nacional/servicios-publicos/Lucha-agua-divide-Atenas-Grecia_0_1440256022.html

Fornaguera, I. (2015a, marzo, 16 de marzo de 2015a). Conflictos por el acceso al agua se desbordan en la Sala IV. La Nación. Recuperado de http://www.nacion.com/nacional/servicios-publicos/Conflictosacceso-desbordan-Sala-IV_0_1475652452.html

Fornaguera, I. (2015b, julio, 13). Aresep: 40\% de Asadas funciona ilegalmente. La Nación. Recuperado de http://www.nacion.com/nacional/Aresep-asadas-opera-ilegalmente_0_1497450249.html

González, M. (2014). Espacio, ritual y estructura social: el amanecer de los mantudos y la espantaperros. Producción social del espacio en la práctica de la diana, San Pedro de Barva, Heredia (Tesis de maestría inédita). Universidad de Costa Rica, San José, Costa Rica.

Grajales, I. (23 de julio de 2014). Municipalidad de Barva busca eliminar junta que reguló cortes de agua. La Prensa Libre, p. 4.

Gutiérrez, F. (19 de junio de 2014). Vecinos de Paraíso de Cartago protestan por falta de agua. La Nación. Recuperado de http:/www.nacion.com/nacional/servicios-publicos/Vecinos-Paraiso-Cartago-protestan-falta_de_agua_0_1421657923.html

Hunt, S., Benford, R. y Snow, D. (2006). Marcos de acción colectiva y campos de identidad en la construcción social de los movimientos. En A. Chihu (ed.), El análisis de los marcos en la sociología de los movimientos sociales (pp.155-188). México D.F.: Universidad Autónoma Metropolitana-Miguel Ángel Porrúa.

Munck, G. (1995). Algunos problemas conceptuales en el estudio de los movimientos sociales. Revista Mexicana de Sociología, 57(3), 17-40.

Oviedo, E. (1 de diciembre de 2013). Labor de Laura Chinchilla permea en la campaña y afecta más a Johnny Araya. La Nación. Recuperado de http:/www.nacion.com/nacional/elecciones2014/LaborLaura-Chinchilla-Johnny-Araya_0_1381661911.html

Pérez, M. (1994). "Cuando lleguen los días de las cólera" (Movimientos sociales, teoría e historia). Zona Abierta, 69, 51-120. Recuperado de http://www.fpabloiglesias.es/0_Resources/zona2.pdf

Raschke, J. (1994). Sobre el concepto de movimiento social. Zona Abierta, (69), 121-135. Recuperado de http://pendientedemigracion.ucm.es/info/cpuno/asoc/profesores/lecturas/raschke.pdf

Ruiz, G. (7 de marzo de 2014). Analistas: PLN está expuesto a "intensa" lucha para llenar vacante en el poder. La Nación. Recuperado de http://www.nacion.com/nacional/elecciones2014/elecciones_2014segunda_ronda-johnny_araya-pln-renuncia_a_aspiracion_presidencial_0_1400860087.html 
Serra, L. (2003). Participación ciudadana y movimientos sociales. Encuentro, 64, 18-36. Recuperado de http://165.98.12.83/579/1/encuentro64articulo2.pdf

Solano, H. (4 de abril de 2014). Contraloría advierte sobre falta de controles en uso de agua que realizan 28 municipalidades. La Nación. Recuperado de http://www.nacion.com/nacional/religion/Contraloriaadvierte-controles-realizan-municipalidades_0_1406459436.html

Svampa, M. (2008). La disputa por el desarrollo: territorio, movimientos de carácter socio-ambiental y discursos dominantes. En M. Svampa (ed.), Cambio de época. Movimientos sociales y poder político (pp. 1-31). Buenos Aires: Siglo XXI. Recuperado de http://maristellasvampa.net/archivos/ensayo43. pdf

Svampa, M. (mayo, 2009). Protesta, movimientos sociales y dimensiones de la acción colectiva en América Latina. Ponencia presentada en las Jornadas de Homenaje a C. Tilly, Universidad Complutense de Madrid, Madrid. Recuperado de http://maristellasvampa.net/archivos/ensayo57.pdf

Tarrow, S. (1997). El poder en movimiento. Los movimientos sociales, la acción colectiva y política. Madrid: Alianza Editorial.

Tilly, C. y Wood, L. (2009). Los movimientos sociales 1768-2008. Desde sus orígenes hasta Facebook. Barcelona: Crítica.

Unión Nacional de Gobiernos Locales. (2013). Código Municipal comentado. Ley $n^{\circ} 7794$. Recuperado de http://ungl.or.cr/sites/all/themes/ungl/img/Codigo-Municipal-2014.pdf 